\title{
Flexural Behavior of Concrete Members Reinforced With 3D- Textile Fibers-A Review
}

\section{Authors affiliations: \\ 1)Civil Engineering \\ Department, Al-Nahrain \\ University, Baghdad-Iraq maysss30@gmail.com}

$\left.2^{*}\right)$ Civil Engineering

Department, Al-Nahrain

University, Baghdad-Iraq

ahmed sltn2007@yahoo.com

\section{Paper History:}

Received: $21^{\text {th }}$ June. 2019

Revised: 24th July. 2019

Accepted: $17^{\text {th }}$ Sep. 2019

\author{
Mays R. Abdulghani ${ }^{1}$, Ahmed S. Ali ${ }^{2 *}$
}

\begin{abstract}
:
Normal concrete is weak against tensile strength, has low ductility and also insignificant resistance to cracking. The addition of diverse types of fibers at specific proportions can enhance the mechanical properties as well as the durability. Discrete fiber, which is commonly used, have many disadvantages such as balling the fiber, random distribution, and limitation of the used Vf ratio. Based on this vision, a new technique was discovered, enhancing concrete by textile-fiber to avoid all the problems mentioned above. This paper presents all important consequence and conclusions obtained from previous studies on how to strengthen concrete with twodimensional and three-dimensional textile-fibers, and focuses on the flexural behavior of concrete members. The results indicate that there was an improvement in flexural strength, deformation capacity, and toughness with different load conditions when using different types of textile-fiber. It was observed that the effect of textile-fibers would increase when this fiber was coated by epoxy. In TRC system, there is a significant impact on the number of textile-fiber layers used.
\end{abstract}

Key words: Normal Strength Concrete, Tensile Strength, Micro-Cracks, Textile Fiber, 3D Textile Reinforced Concrete Fiber.

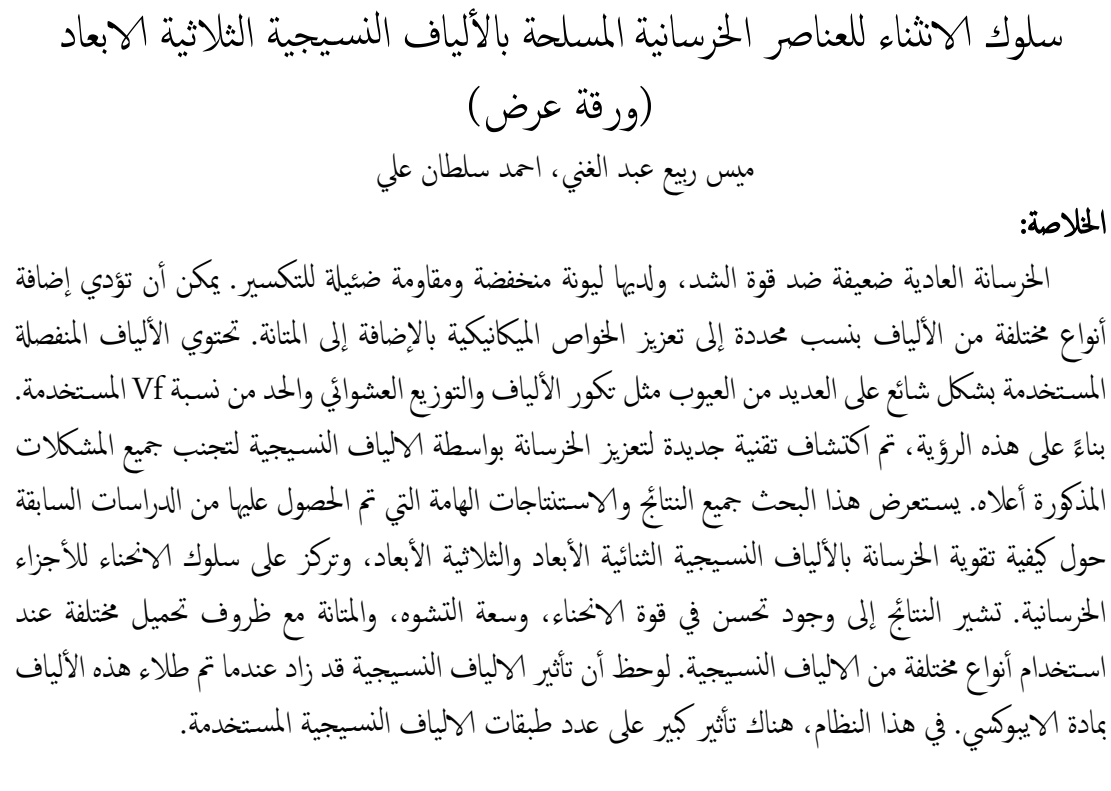

\section{Introduction:}

FRC is described as a concrete that contains randomly distributed fibers. It has been more than 30 years since the beginning of research and developments in fiber reinforced concrete. Romualdi, Patterson, and Mandel published the papers [1.2] in the early 1960s, which contained a study about (FRC), drew the attention of the universities, academic, and industrial researchers around the world. Also, a great number of peoples have focused their attention on the FRC field through the academic degree requirements at each level (undergraduate and postgraduate) by conducting research that contributes to the development of FRC. In addition, there are local seminars, regional symposiums and international conferences held annually around the world, providing 
evidence that there is still a great level of interest in the development of FRC. All of these educational programs provide services to understand what is FRC technique and the possibility of developing it.

\section{Fiber Historical Development:}

In $1500 \mathrm{BC}$, the idea of using fiber for the first time was found by ancient Egyptians who used hair from animals and straw as a reinforcement of brick and masonry walls in housing. Asbestos fibers were improved until 1900s, which were produced and used in general to increase the mechanical properties of the cement matrix indicated by Bentur \& Mindess, (1990), Fibers vary in terms of types, geometry and characteristics that require their availability in the construction industry. (Steel, glass, carbon, and polypropylene) fibers are the most common types of fibers, Figure (1). These uses may vary in concrete for a variety of purposes [3].

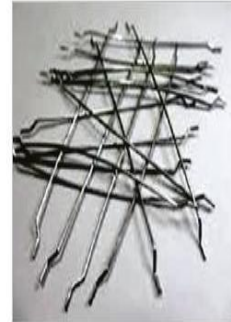

Hooked-end

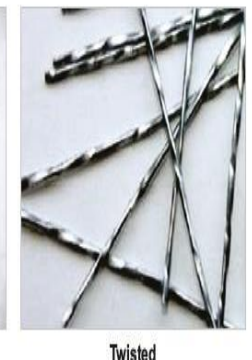

Twisted

Synthetic fibers

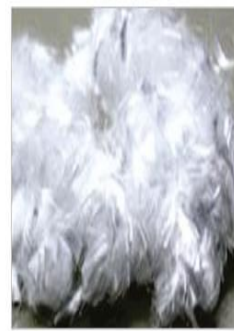

Polypropylene

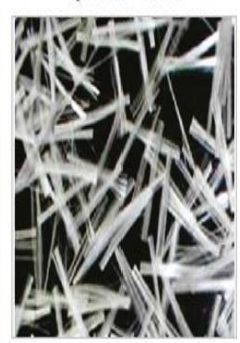

Glass

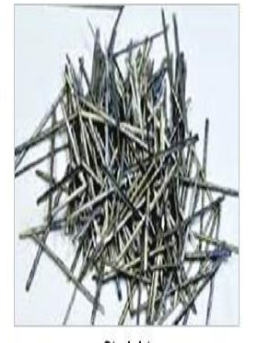

Straight

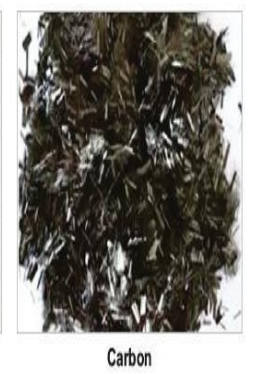

Figure (1): type of discrete fiber [3].

Since fiber is, by definition, randomly added to concrete during the mixing stage, the position and orientation of each isolated fiber depends on the pouring process, and framework geometry. For both steel and polyolefin fibers, strength is directly related to the number of fibers crossing the fracture surface. The number of fibers crossing a certain section is related not only to fiber distribution, but also to fiber orientations. Also, discrete fiber may be balling and fold during the random distribution process. This reduces the proportions that would have been used to enhance the concrete properties. The limits' percentage of adding the used discrete fiber should not exceed $2 \%$, because an increment in this percentage adversely affects the workability of the concrete. All the above-mentioned reasons lead to the using of a new concrete which was produced from high proportions of steel fiber which exceeds $2 \%$. This type of concrete was named SIFCON (Slurry Infiltrated Fiber Reinforcement Concrete), which Lankard Materials Laboratory first developed in 1979, by adding cement-based-cement-compounds to large quantities of steel-fiber. figure (2) demonstrates the slurry infiltration by using the vibrating table [4].

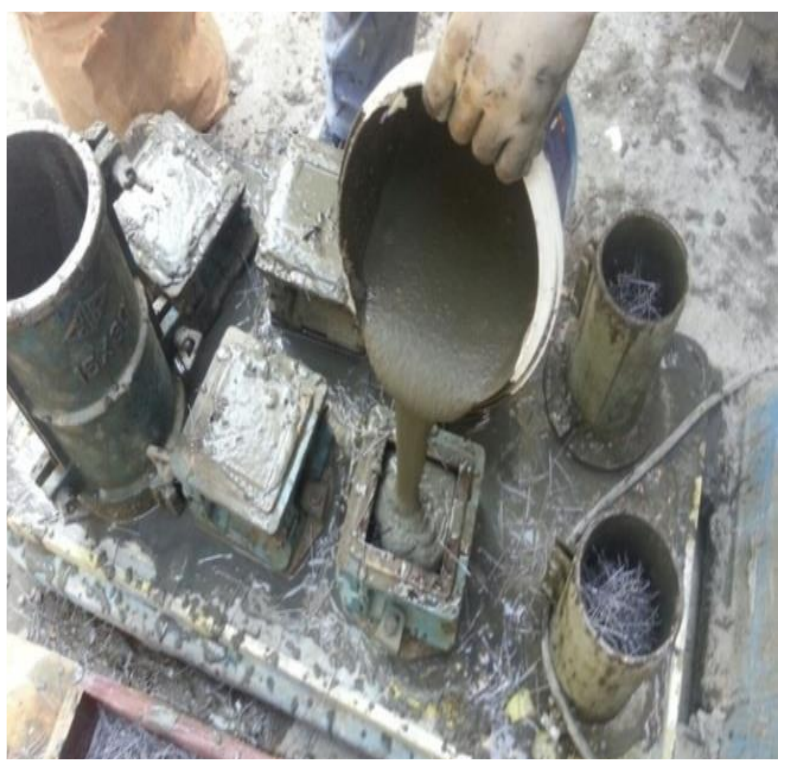

Figure (2): Slurry infiltration through steel-fiber by using external vibration [4]

In some cases, the addition percentage of steel fibers can reach $20 \%$ of the size of the concrete. The way to choose good-infiltration-technique is largely affected by the ease of slurry flows through a layer of packed-fiber. Figure (3) shows what happens when the mortar flow is not sufficiently capable, or when the vibration is not sufficiently high. The number of voids depends on how well the slurry is able to flow, and how strong the vibration is. SIFCON has special requirements to standardize and control the quality of fibers that distribute along with the concrete elements that need this type of concrete. This leads to the need for an additional cost and may reflect the overall budget of the project.

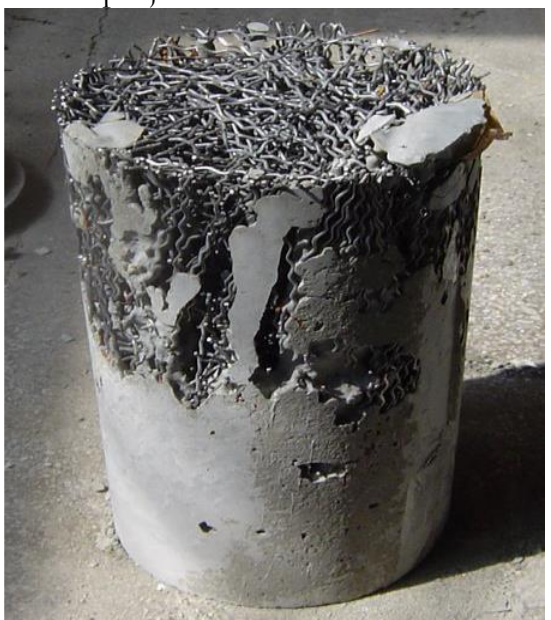

Figure (3): Failed in preparation due to loss of the fluidity of slurry [4].

\section{Textile Fiber Reinforced Concrete:}

A new and innovative attempt of promoting the sustainability of RC is improved with TRC [5]. It has been discovered that TRC could be used to create lightweight and slender structures, as well as to remove the corrosion risk. TRC provides great compression and tensile strength [6]. TRC could be used as a new 
idea of composite material with a great performance, which not only enhances material but load bearing component alone [7]. An investigation has been carried out by Triantafillou et al (2005). He studied the shear behavior of strengthening the structure element by textile carbon fiber. Figure (4) shows the photograph and architecture of the used textile fiber. Six beams $(2.60 \mathrm{~m}$ long and cross section of $150 \times 300$ $\mathrm{mm}$ ) weak in shear (large distances between stirrups in the shear span) was tested monotonically with fourpoint bending [8].
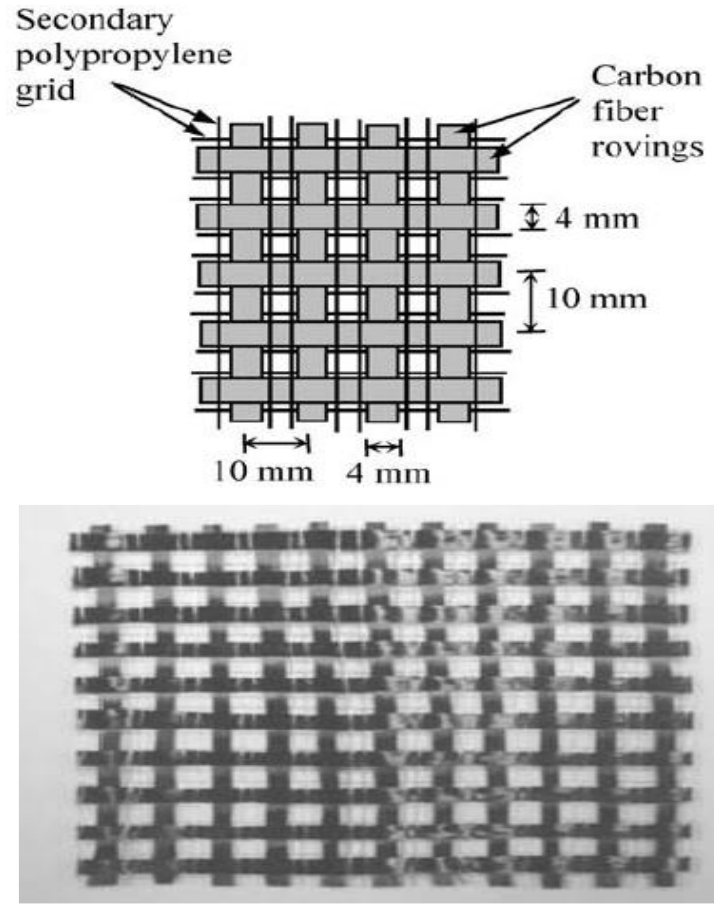

Figure (4): textile carbon fiber [8].

The test results concluded that the textilereinforced mortar covers provide a real gain in the shear capacity for reinforced concrete members. The reinforcement by two layers of mortar-impregnated textile (Nominal thickness of each layer equal to 0.047 $\mathrm{mm}$ in each direction of fibers) gave an increase in the shear strength of the tested beams by more than 60 $\mathrm{kN}$, and therefore preventing the sudden shear failures and allow the activation of flexural yielding. Reinforcement by one layer of textile fiber proved to be less effective but still sufficient to provide a large shear resistance, which is more than the nonstrengthened beam with more than $40 \mathrm{kN}$. Figure (5) shows the setup of the beam for test procedure by applying textile-reinforced-mortar in the shear spans.

Experimentally investigated for the bending behaviors of TRC have been conducted by Hegger et al. (2008). They shaped beams with $(1000 \mathrm{~mm}$ length, $120 \mathrm{~mm}$ high, $110 \mathrm{~mm}$ flanges width, and the placement of the reinforcement was in the center of the components) which has been reinforced with textile-carbon-fiber TCF, and alkali-resistant-textileglass-fiber AR-TGF, and they were tested in fourpoint-load. Flange reinforcement in the tensile zone has been varied with one and three layers of textile fiber while the web reinforcement was always with two layers. The results showed that the reinforcement with textile AR-glass obtained about $410 \mathrm{MPa}$ ultimate strength, while the ultimate strength (with using textile carbon fiber) rose with the raising reinforcement ratio that reached $1100 \mathrm{MPa}$ (for reinforcement with one layer) and reached up to $1400 \mathrm{MPa}$ when the beam was reinforced with three layers [9]. Zhu et al (2009), studied flexural behavior with AR glass TRC for different specimens (beams and plates) and compared the results between them. Textile fibers were immersed in a slurry-infiltration-pan and then dragged out of a set of rollers to compress the slurry-paste through the openings of fabric. Composite plates layers have been formed on rotating mandrel; this process is shown in Figure (6). The cement-based composites have been made of ( 6 and 8 ) layers of textile fiber with reinforcement content of (4.0 and 6.0) $\%$ by volume of AR-TGF, respectively. The results showed that beam specimens have a greater ultimate load with lower deflection as compared with plates specimens because of the coupled effect of the direction of cross-section and the orientation of fabric. For beams' specimens, it's the cross-section and the orientation of the fabric. For beams' specimens, maximum flexural stress rises with the number of textile fiber layers, while in the case of plate the maximum flexural stress was decreased with increasing the number of textile fiber layers because of interlaminar shear failure [10].

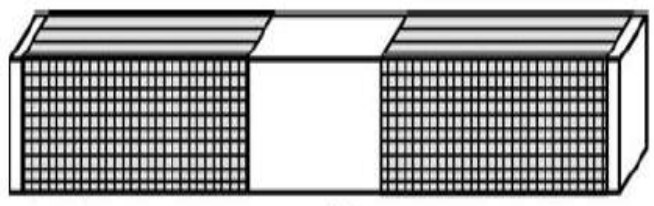

(a)

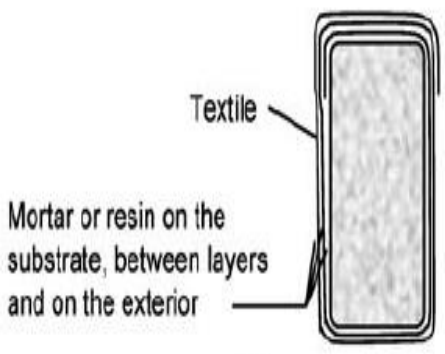

(b)

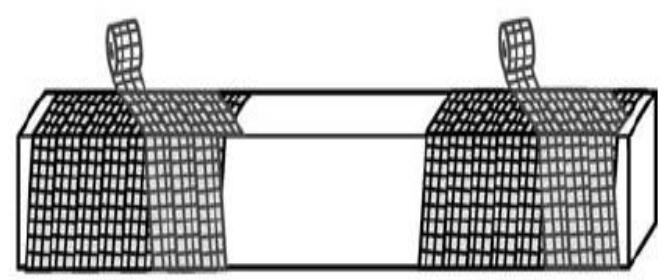

Figure (5): Applying textile-reinforced-mortar in the shear spans: (a) normal cover, (b) more layers of textile with mortar [8]. 


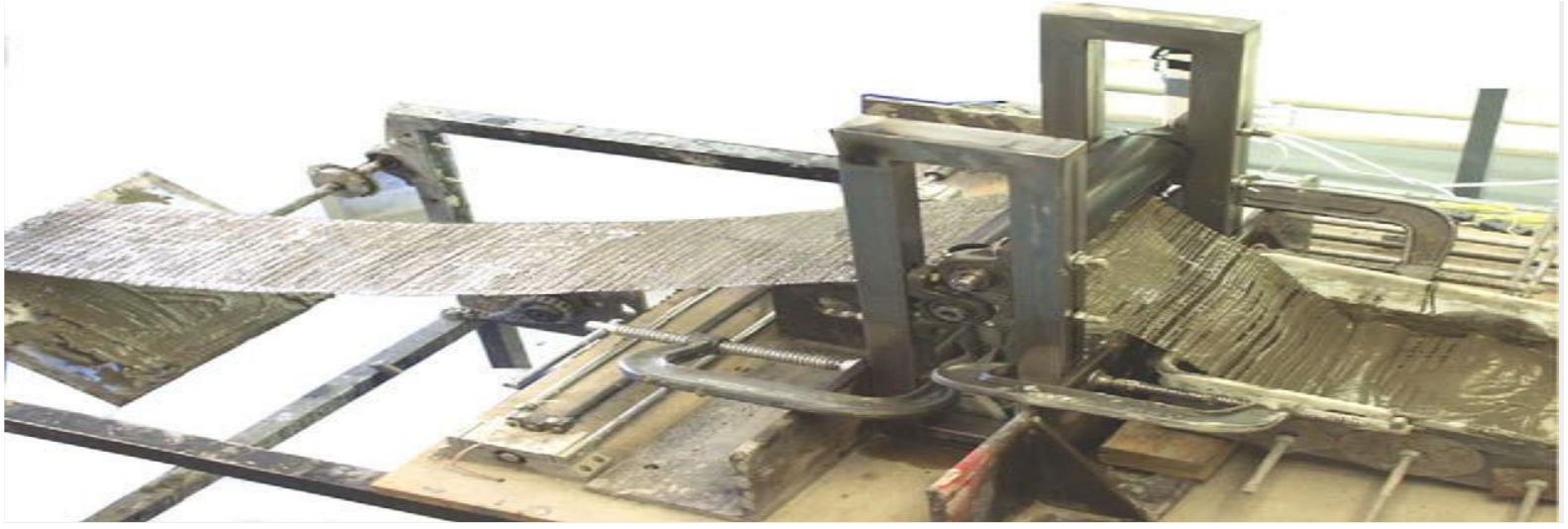

Figure (6): the fabrics dragged out through the cement bath [10].

The effect TRMs as a means of enhancing the bending strength of RC beams was investigated by Elsanadedy et al (2013). Basalt-based textile has been utilized as a strengthening material. The study depended on the number of TRM layers, type of mortar, the kind of strengthening material, and TRM versus composites carbon-fiber-reinforced-polymer CFRP. Six simply supported beams with dimensions of $(150 * 200 * 2000 \mathrm{~mm})$ have been tested with four- point bending until failure occurred. The study showed that the polymer-modified-cementitious-mortar gave best connection between the layers of TRM and concrete substrate when compared with cementitious mortar. The layers of textile -basalts -fibers-reinforcedmortar provided real gain in the bending strength ranged from (39 to 91 ) \%. Figure (7) shows the load deflection curved for the test beams [11].

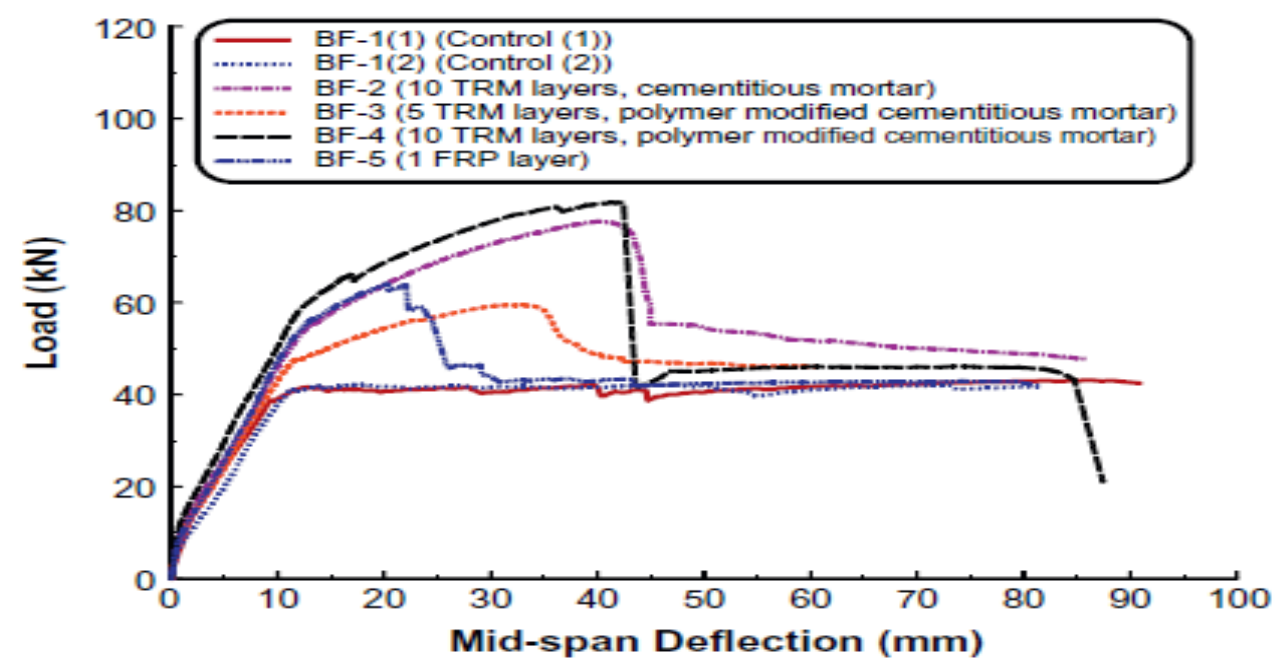

Figure (7): Load-deflection relationship for tested beams [11].

Raoof et al (2017), investigated the flexural behavior of RC beams strengthened with TRMs (textile-reinforced mortar) and FRP (fiber-reinforced polymers) many types of textile fibers were used (coated basalt, carbon or glass fibers). $13 \mathrm{RC}$ beams (1 beam as a control specimen, 7 beams were strengthened with TRM, and 5 with FRP). They have been utilized and tested with four-point bending. This study showed: (A) the increasing of load carrying capacity of TRM beams were less than that of FRP. But also, the effect of TRM was sensitive with the increased number of layers. The effectiveness factor was increased from $(0.47$ to 0.80$)$ when increasing the number of textile fiber layers from (1 to 3). (B) when Coating the textile carbon fibers with epoxy adhesive greatly enhanced the activation of TRM materials. About 55\% enhancement was found when using onelayer of coated textile carbon fiber instead of one-layer of the dry textile carbon fiber. (C) For both the strengthening systems TRM and FRP, the postyielding stiffness and cracks of strengthened beams was greatly enhanced as compared with nonstrengthened beam by about $(72 \%$ and $1298 \%)$, respectively [12].

A study was carried out by Du et al (2018), on the effect of the textile-fiber-layers, levels of prestress for the textile, and the precentage contents of choppedsteel-fibers on the behavior of bending strength for BTRC basalt textile-reinforced concrete plate and was tested with (four-point bending). A specific steel-strips number have been utilized to ensure the symmetry of the thickness of the two-adjacent-layers, as shown in Figure (8). An improvement in bending strength and toughness has been observed with the increased number of fabric layers. The usage of chopped-steelfibers was positively influencing the bending stress at the first-crack stage, bending strength, post-crack bending, stiffness and toughness [7]. 


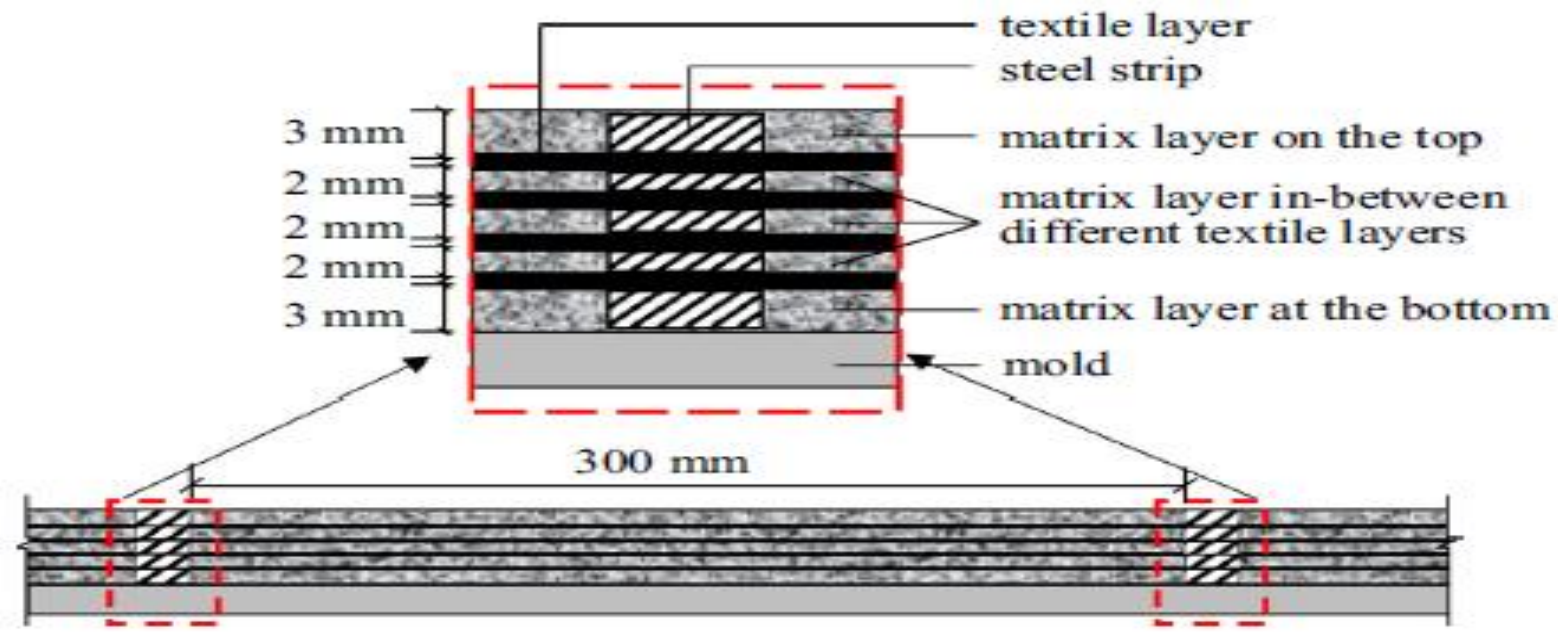

Figure (8): Cross section of four-layer BTRC plates during fabrication [7].

\section{3D-Textile Fiber Reinforced Concrete:}

The 3d textile-fiber reinforced-concrete 3D-TFRC is described as a concrete that contains woven fibers and regularly distributed. The three-dimensional textile fiber is different from the two-dimensional textile fiber as it provides additional resistance against loads in the third direction. It consists of two layers of woven fibers bound together by fiber filaments in the third direction which forms thickness. The technique of the double needle rod has been updated by inserting straight reinforcement filaments installed on the axes on both sides of the fabric. In TRC, ready-made textiles can be utilized instead of single fibers to take full advantage of fiber strength. Because threedimensional textiles can be placed to match the load state in three dimensions, they exhibit a distinct technical and economic behavior.

\subsection{Mechanical Behaviors of 3D-TFRC:}

To realize the structural elements main conduct, which is manufactured from a mixture containing textile-or-separated fibers. It is very important to identify the mechanical-behavior of the concrete mixture that is reinforced with these fibers. In general, the compressive strength $f c u$ is not affected when textile-fiber is utilized, unlike the separate-fibers which have a prominent impact on $f c u$. On the other hand, 3D-TRC is influenced by tensile strength $f c t$. The $f c t$ for 3D-TRC can be calculated by utilizing direct tensile test.

Moneem et al (2018), carried out an investigation about tensile behavior for 3D-TRC, as well as the effect of increasing the textile-fiber-thickness or the number of textile-fiber-layers. Plate samples $(400 * 100$ * 40) $\mathrm{mm}$, were cast and strengthened with 3D-Alkaliresistant-textile-glass fiber 3D-AR-TGF. Three different thickness levels for textile-fiber have been utilized $(6,10$, and 15$) \mathrm{mm}$. the samples were tested under tension load by using direct-tensile test. the improvement in the tensile strength was ranging from 5 to $10 \mathrm{MPa}$ after 28 days of curing, and from 12 to 18 $\mathrm{MPa}$ after 90 days, compared with the reference (nonstrengthened-sample). By comparing the difference in thickness, the tensile strength for sample with $10 \mathrm{~mm}$ thickness was greater by $165 \%$ than that of $6 \mathrm{~mm}$, as well as the samples with $15 \mathrm{~mm}$ textile thickness was greater by $100 \%$ than that of $6 \mathrm{~mm}$. On the other hand, when comparing the difference in the number of textile-fiber-layers, the usage of two-layers was greater than one-layer by (105 and 4) \% for (6 and 10) $\mathrm{mm}$ thickness, respectively [13].

Yoo et al (2015), studied the bending conduct by using 2D-TRC and 3D-TRC beam specimens subjected to static load and compared the flexural behavior with those of hooked steel-fiber-reinforced concrete beams SFRC. The dimensions of the beam specimens were $(100 * 100 * 400) \mathrm{mm}$. Figure (9) shows the shape and geometry of all fibers used. For each of 2D-TRC, 3D-TRC and SFR. Three cylindrical specimens have been tested to calculate the compressive strength (used the same compressive strength for both TRC and SFRC as a textile fiber does not affect the compressive strength). The bending test was carried out depending on the ASTM C 1609. Fourpoints load have been subjected to the samples to determine the bending strength. LVDTs were installed and used to calculate the deflection. This study showed that the usage of 3D-TF gives greater improvement in bending strength and toughness than $2 \mathrm{D}$-TF. In the same time, the usage of $0.5 \%$ of steel-fiber gives greater bending strength and toughness than both 3DTF and 2D-TF [14].

Moneem et al (2018), studied the behavior of 3Dtextile fiber reinforced cementitious composites. The flexural behavior has been studied with selfcompacting mortar reinforcement with $3 \mathrm{D}$ textile AR glass fiber with different thickness levels $(6,10$, and15 $\mathrm{mm})$. The specimens have been tested for two cases; the first was for using 1 layer of textile reinforcement and the other was for using 2 layers of textile reinforcement. The results showed that (A) For 3Dtextile glass fiber with $6 \mathrm{~mm}$, the increment in the flexural strength at 28 days was $32 \%$ for one-layer reinforcement and $68 \%$ for two layers reinforcement. (B) For 3D-textile glass fiber with $10 \mathrm{~mm}$, the flexural strength increases about $(34.19,40.49 \%)$ when one layer and two layers are used, respectively. (C) for 3Dtxtile glass fiber with $15 \mathrm{~mm}$, the increase was about $(50.6,36.18 \%)$ when one layer and two layers are used, respectively [15]. 

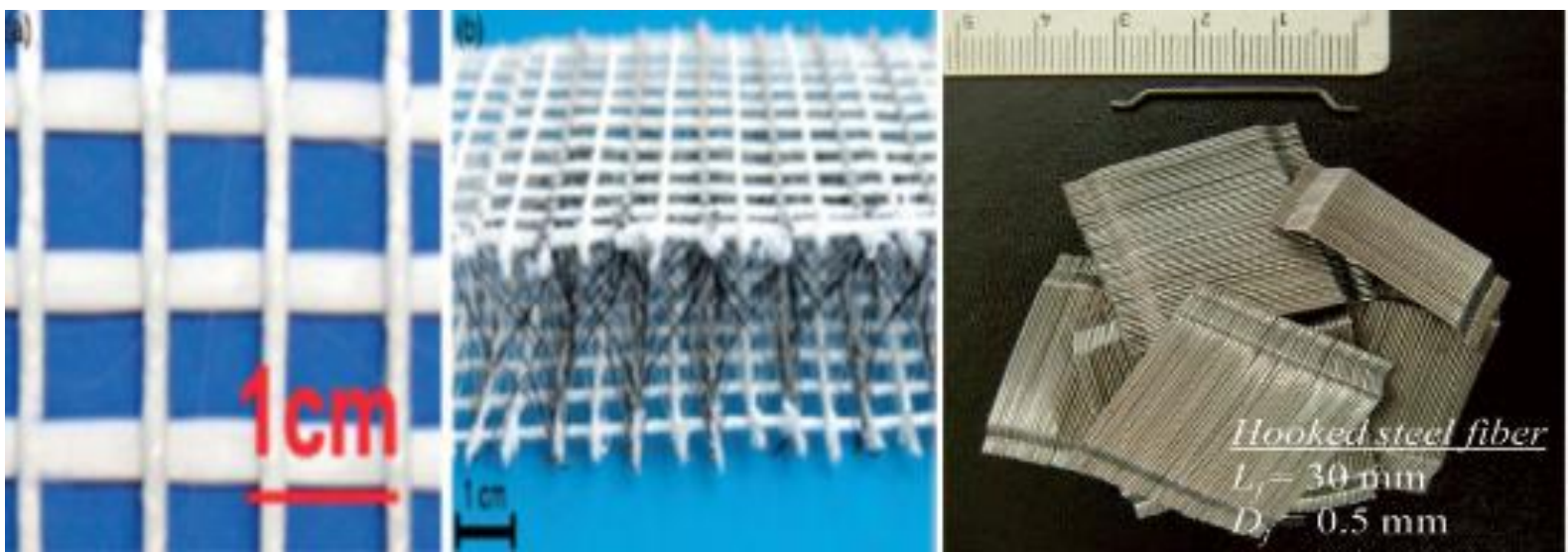

Figure (9): the shape and geometry of (2D, 3D) textile AR glass fiber, and hooks end steel [13].

\section{Conclusion:}

The above studies summarize that TRC could be utilized to create lightweight structures and remove the risk of corrosion. The utilizing of TRC has helped to eliminate problems in discrete fibers such as (nonintersecting of fibers with cracks, balling the fiber during the mixing process, and the restrict of the ratio of fibers used). The compressive strength $f c u$ is not affected by the TRC system. The tensile strength for TRC is calculated by direct tensile test. The usage of TRC with three dimensional gives greater improvement in flexural strength and toughness than the two dimensional. The thickness in the textile-fiber gives the structural element the ability to carry loads in the third direction. The usage of TRC gives a significant improvement in both tensile and bending strengths. the increase in the textile-fiber-thickness helps to improve the flexural strength, as well as the tensile strength. In addition, the increase in the textilefiber-layers lead to enhancing the behavior of flexural and tensile for the structural element.

\section{References:}

[1] Romualdi, J. P. \& Batson, G. B., Mechanics of crack arrest in concrete. Proc. ASCE, 89 EM3 (1963) 147-168.

[2] Romualdi, J. P. \& Mandel, J. A., Tensile strength of concrete affected by uniformly distributed closely spaced short lengths of wire reinforcement. AC1 J. Proc., 61(6) (1964) 657-671.

[3] Bentur A. and Mindess S., "Fiber Reinforced Cementitious Composites", Elsevier Science Publishing Ltd., New York, United State of America, 1990.

[4] Lankard, D.R.,1984 "Preparation, Applications: Slurry Infiltrated Fiber Concrete (SIFCON)", Concrete International, V.6, No.12, pp. 44-47.

[5] Orlowsky J. and Raupach M. "Textile reinforced concrete-from research to application". Cement Wapno Beton, Vol. 16 (6), pp. 323-331. 2011.

[6] Brameshuber W.: Report 36: "Textile Reinforced Concrete-State-of-the-Art Report of Rilem TC" 201TRC.36. Rilem publication. 2006.

[7] Y. Du, X. Zhang, F .Zhou, D. Zhu, M. Zhang, and W. pan, "Flexural behavior of basalt textile- reinforced concrete," Constr. Build Mater., vol 183, pp. 7-21, 2018.

[8] T. C. Triantafillou and C. G. Papanicolaou, "Shear strengthening of reinforced concrete members with textile erinforced mortar (TRM) Jackets, " Mater. Struct. Constr., vol. 39, no. 285, pp. 93-103, 2006.

[9] J. Hegger and S. Voss, "investigations on the bearing behavior and appliction potential of textile reinforced concrete,"Eng. Struct., vol. 30, no. 7, pp. 2050-2056, 2008.

[10] D. Zhu, M. Gencoglu, and B. Mobasher, "Low velocity flexural impact behavior of AR glass fabric reinforced cement composites,"Cem. Concr. Compos., vol 31, no.6, pp. 379-387, 2009.

[11]H. M. Elsanadedy, T. H. Almusallm, S. H. Alsayed, and Y. A. Al-salloum,"flexural behavior of RC beams using textile reinforced mortar-experimental and numerical study, "Compos. Struct., vol.97, pp. 40-55, 2013.

[12] S. M. Raoof, L. N. Koutas, and D. A. Bournas, "Textile-reinforced mortar (TRM) versus fiberreinforced polymers (FRP) in flexural strenghtening of RC beams," Const. Build. Mater.. vol.151, pp.279-291, 2017.

[13] I. GORGIS, W. Abbas, and N. Moneem, " tensile strength of 3D textiles reinforced cementitious composites plates, "MATEC Web Conf. vol. 162, p.004008, 2018.

[14] D. Y. Yoo, U. Gohil, T. Gries, and Y. S. Yoon," Compartive low-velocity mpact response of textile[reinforced concrete and steel finer-reinforced concrete beams, "J. Compos. Mater. vol. 50, no. 17, pp. 2421-2431, 2016.

[15] N. Moneem, I. N. Gorgis, and W. A. Abbas, "investigate the behavior of 3D Textile Fiber Reinforced cementitious compsites plates undar impact load," ARPN J. Eng. Appl. Sci., vol. 13, no. 4, pp. 1188-1201, 2018. 